\title{
2014 College Students' Employment Expectation Prediction Based on ANP
}

\author{
Liying Wang ${ }^{1}$, Jianying $\mathrm{Li}^{2}$ and Qiuxiang $\mathrm{Shi}^{3}$ \\ ${ }^{I}$ Department of Education, Hebei Normal University of Science \& Technology \\ Qinhuangdao, Hebei, P.R.China, 066004 \\ ${ }^{2}$ Department of Education, Hebei Normal University of Science \& Technology \\ Qinhuangdao, Hebei, P.R.China, 066004 \\ ${ }^{3}$ Department of Education, Hebei Normal University of Science \& Technology \\ Qinhuangdao, Hebei, P.R.China, 066004 \\ 140400149@qq.com, $308017808 @ q q . c o m,{ }^{3} 26870628 @ q q . c o m$
}

\begin{abstract}
In our country, higher education is changing from "elite education" to "popular education", and the number of college graduates is in a sharp increase [1]. The basic supply and demand situation of university students' employment market has changed, resulting a series of social problems such as "college students increasingly serious employment problem", "recruitment problem and employment problem coexist". In this context, according to employment environment to predict the college students' employment expectation has become more and more important to the coordination of the social resources. Based on the employment situation factors on the former research, this article classifies college students' employment expectation attributed to education, government departments, enterprises three categories, and then uses the ANP method to predict the 2014 college students' expectation of employment. So not only can draw various expectation of employment ratio, but also can tell how the factors affecting on the choice of the expectation, and find out the key factors, to provide the reference for the adjustment of national employment policy.
\end{abstract}

Key words: Employment Expectation, 2014 College Students, Prediction, ANP

\section{Introduction}

In recent years, with the expansion of enrollment has slowed, the number of university graduates has been controlled within 7 million, according to official reports, the number of university graduates in 2014 will be slightly higher than in 2013, up to 6.99 million [2], But the days when college students are "God's favored one" have gone. The basic supply and demand situation of university students' employment market would not be changed in the next year.

On the other hand, majority of college students is the "after 90", the distinctive characteristics of the time have been more and more obvious on college students: realizing and pursuiting their personal values, they demand for higher income, social status than older students. On the contrary, as the main component of Chinese employers, small enterprises face the recruitment problem. "Recruitment problem and employment problem coexist" has become a major feature of current college students' employment market in China.

As a valuable resource, college students not being full employed, will not only cause a huge waste of social resources, impact on students' personal future, but also can affect the students learning enthusiasm. Therefore, prediction of the employment expectations of 
university students is very important to make the adjustment of employment education mode and recruitment policy.

As the employment problem of university students has become a big problem in our society. The influence factors of employment expectation of college students have become a hot topic in education research.

As early as 1985, Rooster, J.David predicted the priests and the financial industry employment requirement would fall after 1990 as the widely use of automation office technology [3]. Johor, Mood Huzairi suggested graduates should meet the need of the employers' expectations of employment [4]. Gaballah I discussed the change of social development of EU employment environment and education mode, suggested that the rapid evolution of technology would need to "lifelong learning". This will require the labor market to provide appropriate skills and sufficient number of workers. To face this challenge, the traditional mode of education would profoundly change [5].

Chinese scholars' researches on college students' employment and employment expectations occupy a large proportion in the international academic circle.

Ceng Xiangchang thinks employment expectation is attitude towards employment and occupation,basic plan,occupation type,development, achievement and self-expectation[6]. Zhu Xiaomei believes that the employment expectations as a personal employment attitude, influenced by many factors, mainly have two aspects: individual and environmental factors[7]. Zhu Xiaomei, Lian Xi, Chen Ke think that the personal factors and environmental factors influence the students' employment expectations[8]. Liu Xiaoyu discussed the effects of gender and experience to the employment relationship[9]. Chen Hang, Chen Peijun and others have made study on sports, tourism management and medical students' employment expectation[10-15].

The domestic scholars also have made a lot of suggestions, such as: Liu Yijia believes that college students should choose the provinces have better employment situation to develop [16]. Li $\mathrm{Na}$ and others argues that higher education should improve in three aspects: college students, education institutions and the social, to promote the level of the employment of university students [17-19].

From the above description is not difficult to find out the studies abroad are different from domestic environment, and lack of reference, but the domestic study of this issue almost all talk about the policy and theory, lack of empirical research, cannot find out how the factors affecting the employment environment and the key factors.

In order to provide objective research results to facilitate the government and university`s decision-making department, this paper perspectives from the factors effects employment environmental, to classify the employment expectations of students into education, employment and government departments three categories, then uses the network layer analysis to forecast college students' employment expectations in 2014. So not only can draw various expectation of employment ratio, but also can tell how the factors affecting on the choice of the expectation, and find out the key factors, to provides reference for the adjustment of national employment policy.

This paper is structured as follows:

The first section, the domestic and foreign research on employment ability is briefly introduced, and analysis the necessity of this research.

In the second section, the related theory and application of analytic hierarchy process.

The third section is the relevant theory and application of ANP.

In the fourth section, 2014 college students' employment expectation prediction based on ANP.

The research steps as followed figure. 


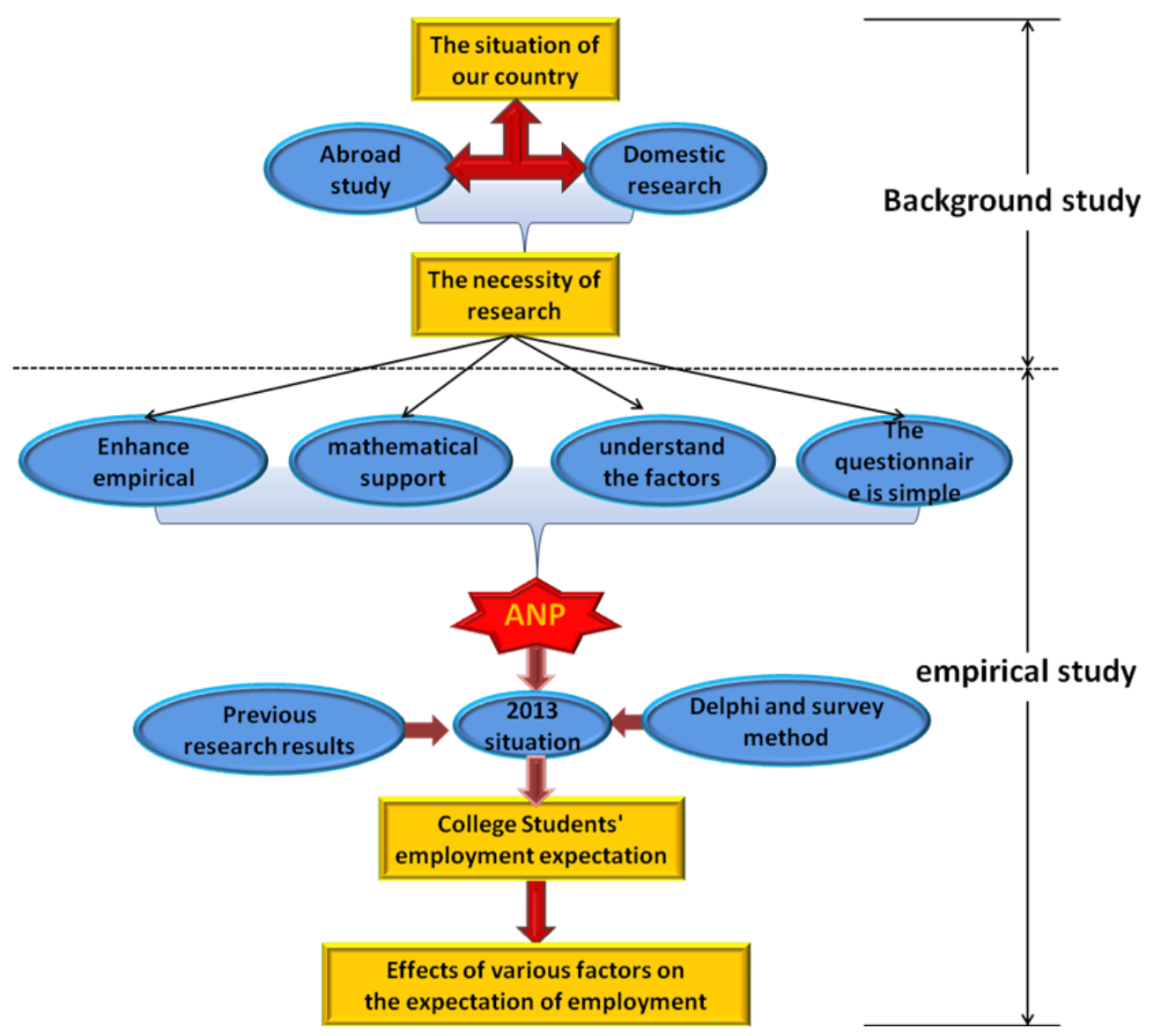

Figure 1. Research Steps

\section{AHP}

Analytic hierarchy process analysis is a method for multi objective decision making problems. The characteristic of the analytic hierarchy process method is on the base of the analysis of complex decision problems, its inherent relationship between factors and so on, then use less quantitative information to decision-making process of mathematical thinking, to provide more objective decision for multi criteria or no structural properties of complex decision problems, particularly suitable for the decision is difficult to measure.

In the real world, the problems such as how to select the tourist attractions, chooses a college application. Before making the final decision, the decision makers must consider many factors and criteria, the ultimate choice made by these criteria. These factors are interdependent, mutual influence. This complex system will called a decision system. In these decision systems, factors often cannot describe with quantitative way. At this time will need to take semi qualitative, semi quantitative problems into quantitative calculation. AHP is an effectual method to solve this kind of problem.

\section{ANP}

AHP and ANP are methods to solve the decision problem of non structure and semi structure, and this type of decision is the most decisive problem. This is a generic feature of AHP and ANP. Theoretical support for ANP is AHP, and ANP is development of AHP, but we also can say that AHP is a special case of ANP[20-24]. 


\subsection{The Analysis of the Structure of ANP}

The elements of the ANP system are divided into two parts. The first part is called the control layer, including target and decision criteria. All the criteria were found to be independent of one another, and only controlled by the target element. Control layer can be no decision criteria, but have at least one target. The second part is the net layer, which is composed of the entire control layer element. The internal structure of the net layer is mutual influence. Figure 2 is a typical ANP structure.

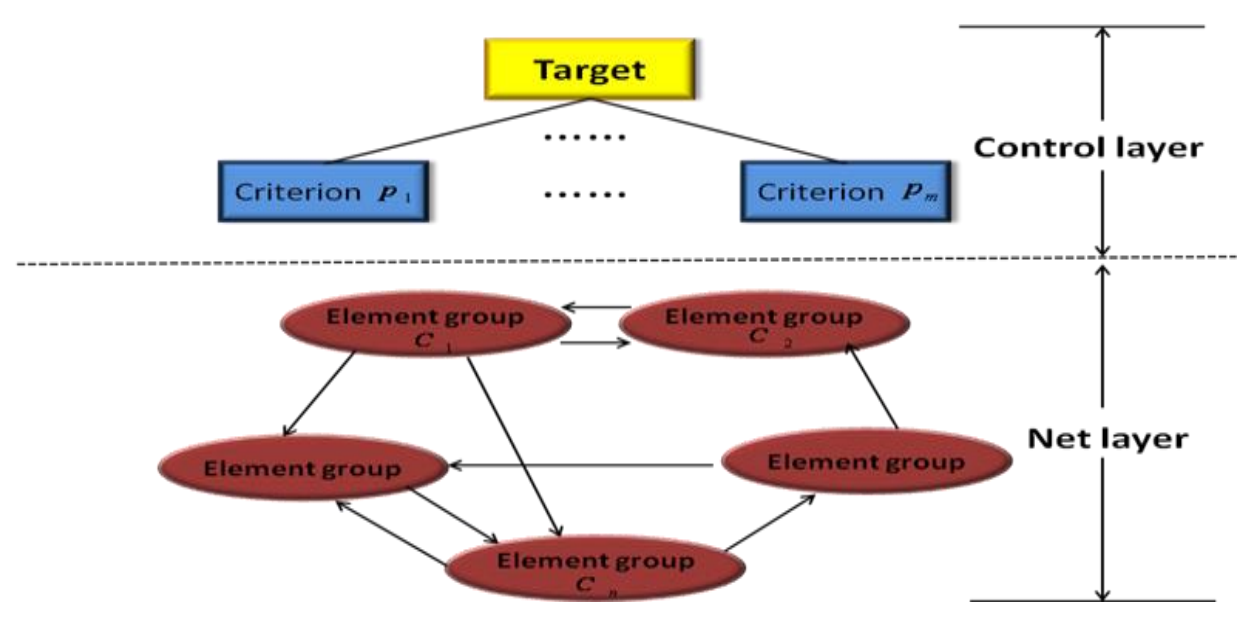

Figure 2. Typical ANP Structure

\subsection{The Basic Steps for Using ANP Model}

The first step: analysis. Analyze the decision problem; combine the elements and element sets.

This step is very important, classifying has to be correct. The main analysis is to determine whether the internal element is independent, analysis of the ANP problem is similar to the AHP method.

The second step is to construct a typical ANP structure. We first construct the control

level, to define the decision goal. Then define the decision criterion.

The third step is to construct the ANP super weight matrix. The core work of ANP: solution of super matrix is a very complex computation process, it is too difficult for manual operation, and the practical application is to use computer software, such as Super Decision.

\subsection{The ANP Structure of the Super Matrix and Weighted Super Matrix}

As shown in Figure 2, there are elements of $p_{1} p_{2}$ in control layer, and in net layer are the elements of group $C_{1} C_{2} \ldots C_{n} . C_{1}$ has elements of $e_{i 1} e_{i 2} \quad e_{i n}$, where $i=1,2, \cdots, n$.

Take $p_{s}(s=1,2, \cdots, m)$ as the main criteria, the $C_{j}$ element $e_{j l} l=1,2, \cdots, n_{j}$ as the second criteria, constructing judgment matrix:

For $p_{s}$ : 


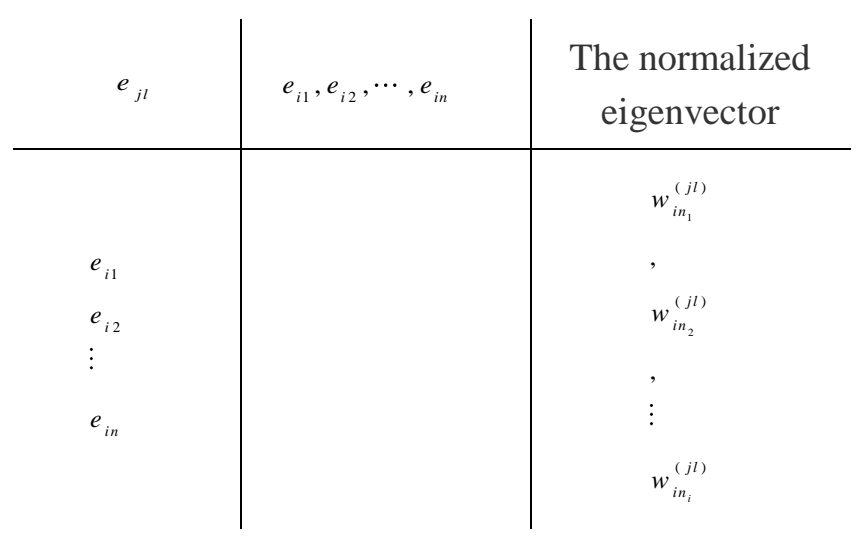

By the characteristic root method we can sort vector $\left(w_{i 1}^{(j l)}, w_{i 2}^{(j l)}, \cdots, w_{i i_{i}}^{(j l)}\right)$. Let $w_{i j}$ be

$$
W_{i j}=\left[\begin{array}{cccc}
w_{i 1}^{(j 1)} & w_{i 1}^{(j 2)} & \cdots & w_{i 1}^{\left(j n_{j}\right)} \\
w_{i 2}^{(j 1)} & w_{i 2}^{(j 2)} & \cdots & w_{i 2}^{\left(j n_{j}\right)} \\
\vdots & \vdots & \vdots & \vdots \\
w_{i n_{i}}^{(j 1)} & w_{i n_{i}}^{(j 2)} & \cdots & w_{i n_{i}}^{\left(j n_{j}\right)}
\end{array}\right]
$$

The influence element column vector of $W_{i j}$ is $C_{i} e_{i j} \cdots e_{i i_{i}}$ for $C_{j}$ elements $e_{j i} \cdots e_{j m_{j}}$ in the ranking vector. If $C_{j}$ element is not affected by the elements in the $C_{i}, W_{i j}=0$. Eventually can obtain super matrix $W$

$$
\begin{aligned}
& 1^{\cdots} n_{1} \quad 1 \cdots n_{2} \quad \cdots \quad 1 \cdots n_{N} \\
& { }^{\cdots}{ }^{\cdots} n_{1} \quad W_{11} \quad W_{12} \quad \cdots \quad W_{1 n} \\
& W=1 \begin{array}{llllll}
\cdots & n_{2} & W_{21} & W_{22} & \cdots & W_{2 n}
\end{array} \\
& 1^{\cdots} n_{N} \quad W_{n 1} \quad W_{n 2} \quad \cdots \quad W_{n n}
\end{aligned}
$$

There are $m$ super matrixes, they are all non negative matrix. Super matrix sub block $W_{i j}$ is renormalized, but $W$ is not listed in the normalized, taking $p_{s}$ as the criterion, to each element $p_{1}$ on the criterion of $C_{j}(j=1,2, \cdots n)$ the comparison importance of. $p_{s}$

\begin{tabular}{l|c|c}
$C_{j}$ & $C_{1}, C_{2}, \cdots, C_{n}$ & $\begin{array}{c}\text { The normalized } \\
\text { eigenvector }\end{array}$ \\
\hline$C_{1}$ & & $a_{1 j}$ \\
$C_{2}$ & $j=1,2, \cdots, n$ & $a_{2 j}$ \\
$\vdots$ & $\vdots$ \\
$C_{n}$ & & $a_{n j}$
\end{tabular}

The independent groups of elements ranking vector is zero, the weighted matrix ${ }^{A}$ 


$$
A=\left\{\begin{array}{cccc}
a_{11} & a_{12} & \cdots & a_{1 n} \\
a_{21} & a_{22} & \cdots & a_{2 n} \\
\vdots & \vdots & \vdots & \vdots \\
a_{n 1} & a_{n 2} & \cdots & a_{n n}
\end{array}\right]
$$

\section{2014 College Students Employment Expectation Prediction Based on ANP}

Undoubtedly, college students`employment expectation has played an important role to the social employment policy adjustment. However, the present study in this field mainly adopts the questionnaire method. Although questionnaire method can obtain employment expectations, for the investigation is often directly to select the kind of occupation, so it's difficult to understand the effects of each factor. Using the ANP method to predict, not only can get the employment expectations of university students, but also can understand the impacts of factors in the process of calculation.

Generally speaking, college graduates can be classified into three categories: to study, expecting to become civil servants, to entry the enterprises. This paper will use the Huang Juan research as basic factors, and then to analysis.

Control layer factors are: social factors $p_{1}$, school factors $p_{2}$, family factors $p_{3}$, individual factors $p_{4}$, and the employment situation $p_{5}$.

The network layer factors:

The influence of social factors

(1) The expectation of economic condition $C_{11}$. The economic difference between areas will cause the differences of students' employment, but for the flow of talent is stronger, the economic difference between areas has little effect on the national employment, so we can say the national economic situation influences the employment of university students. The economic situation expected good or bad can directly affect employment of university students, so it is different from Huang Juan's original research, this paper will take the national economy expectation as one of the factors.

(2) The national employment policy expectations $C_{12}$. With the nationwide situation, the expected employment policy for college students undoubtedly plays an important role. Especially the state has put forward a series of economic, political reform measures in this year. These measures have more or less effects on the employment of college students.

Influence of school factors.

(1) Major settings $C_{21}$. Because the university graduates`employment directions are highly related with their major, therefore, major set in Colleges and universities has become one of the factors affecting the employment of graduates.

(2) The curriculum $C_{22}$. Nowadays many universities` public basic courses, such as the introduction to Mao Zedong thought, Deng Xiaoping theory occupies a large proportion of study. In addition, the english requirements are very strict, in many universities, whether can gain graduation certificate is linked with obtain the certification of the Collage English Test Band 4 or 6 . But college students need to learn more professional knowledge. According to the Third Plenary Session of 18th, the national education have to reduce some public basic courses, therefore, it is bound to affects the choice of students' employment.

(3) The quality of teaching $C_{23}$. The quality of teaching in colleges and universities of our country plays an important role for students to choose whether go on to study.

(4) The employment guidance $C_{24}$. For students' employment choice, effective employment guidance plays a vital role. 
Influence of family factors

(1) The income per capita $C_{31}$. The per capita income can reflect the student's family income, in fact, due to the activities of employment required to produce a certain cost, the higher family`s income, employment choice surface is larger, in addition the per capita income also indirectly affects the employment salary expectation. Therefore, the level of per capita income has to be included in the prediction of the employment expectation.

(2) Effects of parental employment concept $C_{32}$, in Chinese tradition, parents have very important influence on their children. They even make choice for their children at the beginning, which will deeply affect the choice of employment of college students. So it is necessary to consider the parent's employment concept as a factor.

The influence of individual factors

(1) Ability $C_{41}$. Ability includes two aspects: professional quality and basic quality. Professional quality refers to the professional knowledge and ability, and basic quality refers to the knowledge and ability a person should have to survive in society. Its range is very wide.

(2) The knowledge of employment $C_{42}$. Employment knowledge directly determines student's employment result, which also influences the employment expectation. A lot of students cannot find a job at the beginning due to not view him objectively.

(3) The employment consciousness $C_{43}$. It is a factor that influences the employment expectation.

(4) The concept of employment $C_{44}$. The concepts of various types of employment expectations have a direct impact on the choice of employment expectation.

Effect of the employment situation

(1) Signing rate $C_{51}$, the older student signing rate directly affects students`expectation of employment.

(2) The compensation level $C_{52}$, the salary level can also influences the students' employment expectation.

Through the analysis:

Control factors: long-term economic and social development can impact on the school and family factors, therefore, control factors are independent of each other in short term. Based on the development in China in 2013 and the AHP method, invites experts to score, the control layer weights are as follows:

\begin{tabular}{|c|c|c|c|c|c|c|c|}
\hline & & ocial factors $\quad p_{3}$ & school factors & $p_{2}$ family factors & $p_{3}$ individual factors & $p_{4}$ & employment stituation \\
\hline social factors & $p_{3}$ & 1 & 5 & 9 & 3 & & 7 \\
\hline school factors & $p_{2}$ & $\frac{1}{5}$ & 1 & 7 & $\frac{1}{5}$ & & 3 \\
\hline family factors & $p_{1}$ & $\frac{1}{9}$ & $\frac{1}{7}$ & 1 & $\frac{1}{7}$ & & 5 \\
\hline individual factors & $p_{4}$ & $\frac{1}{3}$ & 5 & 7 & 1 & & $\frac{1}{3}$ \\
\hline \multirow[t]{3}{*}{ employment stitua } & $p_{5}$ & $\frac{1}{7}$ & $\frac{1}{3}$ & $\frac{1}{5}$ & 3 & & 1 \\
\hline & & $p_{3}$ & $p_{2}$ & $p_{3}$ & $p_{4}$ & & $p_{3}$ \\
\hline & ght $=$ & 0.452 & 0.118 & 0.029 & 0.343 & & 0.058 \\
\hline
\end{tabular}

$\lambda_{\max }=5.093 C_{I}=0.028 R_{I}=1.12 C R=0.032<0.1$ To meet the consistency test

In the net layer, economic condition expectation and employment policy expectation can influence each other, so they are not independent, the quality of teaching, curriculum, professional setting and employment guidance are mutual influence, major setting and 
employment guidance are also associated with the economic situation expectation and employment policy expectation, so they are not independent, per capita income and parents` employment outlook have little influence on each other, so they are independent, individual factors ability and the employment idea influence each other, so they are not independent, the employment of knowledge and awareness of employment influence each other, expected employment concept, employment consciousness, economic status and employment guidance are associated, so they are not independent. The employment situation is independent of each other. Relationship between various factors as Figure 3.

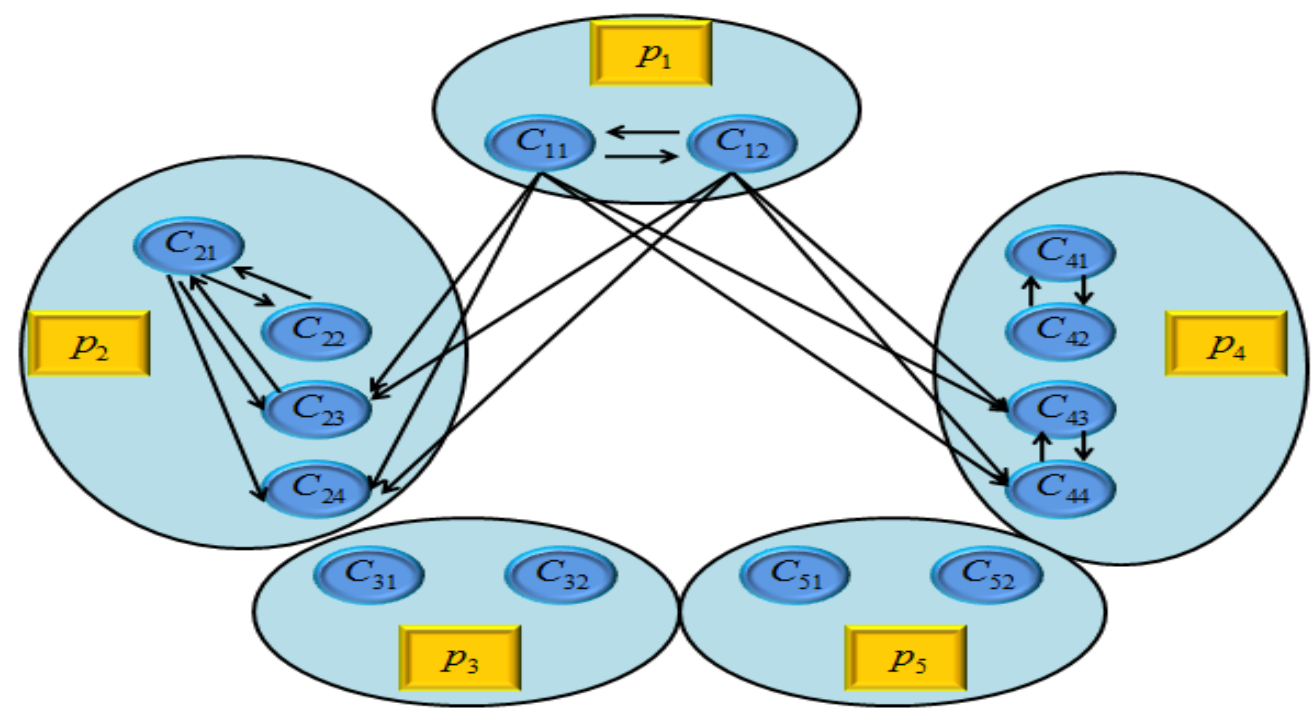

Figure 3. Factor Diagram

Considering the relationships between factors, as well as the influences of study, entering enterprises and civil servants three kinds expectation of employment weights, based on a survey of college students and experts on the basis of Chinese 2013 national conditions, obtain the normalized data super matrix as Table 1:

Table 1. Super Matrix

\begin{tabular}{|c|c|c|c|c|c|c|c|c|c|}
\hline & & \multicolumn{2}{|c|}{$p_{1}$} & \multicolumn{4}{|c|}{$p_{2}$} & \multicolumn{2}{|c|}{$p_{3}$} \\
\hline & & $C_{11}$ & $C_{12}$ & $C_{21}$ & $C_{22}$ & $C_{23}$ & $C_{24}$ & $C_{31}$ & $C_{32}$ \\
\hline \multirow{2}{*}{$p_{1}$} & $C_{11}$ & 0.0000 & 0.7500 & 0.0000 & 0.0000 & 0.1670 & 0.6550 & 0.0000 & 0.0000 \\
\hline & $C_{12}$ & 0.6370 & 0.0000 & 0.0000 & 0.0000 & 0.1670 & 0.1430 & 0.0000 & 0.0000 \\
\hline \multirow{4}{*}{$p_{2}$} & $C_{21}$ & 0.0000 & 0.0000 & 0.0000 & 0.2850 & 0.8330 & 0.0000 & 0.0000 & 0.0000 \\
\hline & $C_{22}$ & 0.0000 & 0.0000 & 0.1880 & 0.0000 & 0.0000 & 0.0000 & 0.0000 & 0.0000 \\
\hline & $C_{23}$ & 0.0530 & 0.1710 & 0.0810 & 0.0000 & 0.0000 & 0.0000 & 0.0000 & 0.0000 \\
\hline & $C_{24}$ & 0.1170 & 0.0780 & 0.7310 & 0.0000 & 0.0000 & 0.0000 & 0.0000 & 0.0000 \\
\hline \multirow{2}{*}{$p_{3}$} & $C_{31}$ & 0.0000 & 0.0000 & 0.0000 & 0.0000 & 0.0000 & 0.0000 & 0.0000 & 0.0000 \\
\hline & $C_{32}$ & 0.0000 & 0.0000 & 0.0000 & 0.0000 & 0.0000 & 0.0000 & 0.0000 & 0.0000 \\
\hline$p_{4}$ & $C_{41}$ & 0.0000 & 0.0000 & 0.0000 & 0.0000 & 0.0000 & 0.0000 & 0.0000 & 0.0000 \\
\hline
\end{tabular}




\begin{tabular}{|c|c|c|c|c|c|c|c|c|c|}
\hline & $C_{42}$ & 0.0000 & 0.0000 & 0.0000 & 0.0000 & 0.0000 & 0.6270 & 0.0000 & 0.0000 \\
\hline & $C_{43}$ & 0.0750 & 0.0810 & 0.0000 & 0.0000 & 0.0000 & 0.0000 & 0.0000 & 0.0000 \\
\hline & $C_{44}$ & 0.7500 & 0.7310 & 0.0000 & 0.0000 & 0.0000 & 0.0000 & 0.0000 & 0.0000 \\
\hline \multirow{2}{*}{$p_{5}$} & $C_{51}$ & 0.0000 & 0.0000 & 0.0000 & 0.0000 & 0.0000 & 0.0000 & 0.0000 & 0.0000 \\
\hline & $C_{52}$ & 0.0000 & 0.0000 & 0.0000 & 0.0000 & 0.0000 & 0.0000 & 0.0000 & 0.0000 \\
\hline \multirow{5}{*}{$\begin{array}{l}\text { Employment } \\
\text { expectation }\end{array}$} & $\begin{array}{l}\text { Higher } \\
\text { school }\end{array}$ & 0.3110 & 0.5000 & 0.0990 & 0.5280 & 0.9500 & 0.0950 & 0.1010 & 0.1960 \\
\hline & Enterprise & 0.1960 & 0.2500 & 0.3640 & 0.1400 & 0.2500 & 0.2500 & 0.2260 & 0.3110 \\
\hline & $\begin{array}{c}\text { Civil } \\
\text { servant }\end{array}$ & 0.4930 & 0.2500 & 0.5370 & 0.3330 & 0.6550 & 0.6550 & 0.6740 & 0.4940 \\
\hline & \multicolumn{4}{|c|}{$p_{4}$} & \multicolumn{2}{|l|}{$p_{5}$} & \multicolumn{3}{|c|}{ Employment expectation } \\
\hline & $C_{41}$ & $C_{42}$ & $C_{43}$ & $C_{44}$ & $C_{51}$ & $C_{52}$ & $\begin{array}{l}\text { Higher } \\
\text { school }\end{array}$ & Enterprise & $\begin{array}{c}\text { Civil } \\
\text { servant }\end{array}$ \\
\hline$C_{11}$ & 0.0000 & 0.0000 & 0.3110 & 0.8570 & 0.0000 & 0.0000 & 0.1570 & 0.0510 & 0.1590 \\
\hline$C_{12}$ & 0.0000 & 0.0000 & 0.1670 & 0.1430 & 0.0000 & 0.0000 & 0.2760 & 0.1100 & 0.3330 \\
\hline$C_{21}$ & 0.0000 & 0.0000 & 0.0000 & 0.0000 & 0.0000 & 0.0000 & 0.0640 & 0.1400 & 0.0480 \\
\hline$C_{22}$ & 0.0000 & 0.0000 & 0.0000 & 0.0000 & 0.0000 & 0.0000 & 0.0650 & 0.1430 & 0.0240 \\
\hline$C_{23}$ & 0.0000 & 0.0000 & 0.0000 & 0.0000 & 0.0000 & 0.0000 & 0.1420 & 0.2240 & 0.1070 \\
\hline$C_{24}$ & 0.0000 & 0.0000 & 0.0000 & 0.0000 & 0.0000 & 0.0000 & 0.0300 & 0.2390 & $\mathbf{0 . 0 3 3 0}$ \\
\hline$C_{31}$ & 0.0000 & 0.0000 & 0.0000 & 0.0000 & 0.0000 & 0.0000 & 0.2070 & 0.0420 & 0.2230 \\
\hline$C_{32}$ & 0.8330 & 0.0000 & 0.0000 & 0.0000 & 0.0000 & 0.0000 & 0.5900 & 0.0510 & 0.0740 \\
\hline$C_{41}$ & 0.0000 & 0.6550 & 0.0000 & 0.0000 & 0.0000 & 0.0000 & 0.0940 & 0.6490 & 0.5280 \\
\hline$C_{42}$ & 0.0000 & 0.0000 & 0.0000 & 0.6270 & 0.0000 & 0.0000 & 0.2800 & 0.0720 & 0.1400 \\
\hline$C_{43}$ & 0.0000 & 0.0000 & 0.7100 & 0.0000 & 0.0000 & 0.0000 & 0.6270 & 0.2790 & 0.3320 \\
\hline$C_{44}$ & 0.0000 & 0.0000 & 0.0000 & 0.0000 & 0.0000 & 0.0000 & 0.6490 & 0.7090 & 0.6610 \\
\hline$C_{51}$ & 0.0000 & 0.0000 & 0.0000 & 0.0000 & 0.0000 & 0.0000 & 0.0720 & 0.1130 & 0.1310 \\
\hline$C_{52}$ & 0.0000 & 0.0000 & 0.0000 & 0.0000 & 0.0000 & 0.0000 & 0.2790 & 0.1790 & 0.2080 \\
\hline $\begin{array}{l}\text { Higher } \\
\text { school }\end{array}$ & 0.2760 & 0.6050 & 0.5940 & 0.0880 & 0.0880 & 0.1170 & 0.0000 & 0.1670 & 0.2000 \\
\hline Enterprise & 0.1280 & 0.1050 & 0.1570 & 0.1950 & 0.1950 & 0.2680 & 0.2500 & 0.0000 & 0.8000 \\
\hline Civil servant & 0.5950 & 0.2910 & 0.2490 & 0.7170 & 0.7170 & 0.6140 & 0.7500 & 0.8330 & 0.0000 \\
\hline
\end{tabular}

Super matrix weighted as Table 2:

Table 2. Weighted Super Matrix

\begin{tabular}{|c|l|c|c|c|c|c|r|r|r|}
\hline \multirow{2}{*}{} & \multicolumn{2}{|c|}{$p_{1}$} & \multicolumn{5}{c|}{$p_{2}$} & \multicolumn{2}{c|}{$p_{3}$} \\
\cline { 3 - 10 } & $C_{11}$ & $C_{12}$ & $C_{21}$ & $C_{22}$ & $C_{23}$ & $C_{24}$ & $C_{31}$ & $C_{32}$ \\
\hline \multirow{2}{*}{$p_{1}$} & $C_{11}$ & 0.0000 & 0.4544 & 0.0000 & 0.0000 & 0.0110 & 0.3964 & 0.0000 & 0.0000 \\
\cline { 2 - 10 }$y$ & $C_{12}$ & 0.1262 & 0.0000 & 0.0000 & 0.0000 & 0.1014 & 0.0715 & 0.0000 & 0.0000 \\
\hline$p_{2}$ & $C_{21}$ & 0.0000 & 0.0000 & 0.0000 & 0.1725 & 0.5056 & 0.0000 & 0.0000 & 0.0000 \\
\hline
\end{tabular}




\begin{tabular}{|c|c|c|c|c|c|c|c|c|c|}
\hline & $C_{22}$ & 0.0000 & 0.0000 & 0.1138 & 0.0000 & 0.0000 & 0.0000 & 0.0000 & 0.0000 \\
\hline & $C_{23}$ & 0.0105 & 0.1036 & 0.0490 & 0.0000 & 0.0000 & 0.0000 & 0.0000 & 0.0000 \\
\hline & $C_{24}$ & 0.0232 & 0.0473 & 0.4426 & 0.0000 & 0.0000 & 0.0000 & 0.0000 & 0.0000 \\
\hline \multirow{2}{*}{$p_{3}$} & $C_{31}$ & 0.0000 & 0.0000 & 0.0000 & 0.0000 & 0.0000 & 0.0000 & 0.0000 & 0.0000 \\
\hline & $C_{32}$ & 0.0000 & 0.0000 & 0.0000 & 0.0000 & 0.0000 & 0.0000 & 0.0000 & 0.0000 \\
\hline \multirow{4}{*}{$p_{4}$} & $C_{41}$ & 0.0000 & 0.0000 & 0.0000 & 0.0000 & 0.0000 & 0.0000 & 0.0000 & 0.0000 \\
\hline & $C_{42}$ & 0.0000 & 0.0000 & 0.0000 & 0.0000 & 0.0000 & 0.0414 & 0.0000 & 0.0000 \\
\hline & $C_{43}$ & 0.0050 & 0.0490 & 0.0000 & 0.0000 & 0.0000 & 0.0000 & 0.0000 & 0.0000 \\
\hline & $C_{44}$ & 0.4554 & 0.4426 & 0.0000 & 0.0000 & 0.0000 & 0.0000 & 0.0000 & 0.0000 \\
\hline \multirow{2}{*}{$p_{5}$} & $C_{51}$ & 0.1038 & 0.0000 & 0.0000 & 0.0000 & 0.0000 & 0.0000 & 0.0000 & 0.0000 \\
\hline & $C_{52}$ & 0.0474 & 0.0000 & 0.0000 & 0.0000 & 0.0000 & 0.0000 & 0.0000 & 0.0000 \\
\hline \multirow{5}{*}{$\begin{array}{l}\text { Employment } \\
\text { expectation }\end{array}$} & $\begin{array}{l}\text { Higher } \\
\text { school }\end{array}$ & 0.0253 & 0.0987 & 0.1436 & 0.0552 & 0.2500 & 0.0323 & 0.0291 & 0.1226 \\
\hline & Enterprise & 0.0636 & 0.0987 & 0.2118 & 0.1313 & 0.6550 & 0.0845 & 0.0869 & 0.1948 \\
\hline & $\begin{array}{c}\text { Civil } \\
\text { servant }\end{array}$ & 0.0401 & 0.1974 & 0.0391 & 0.2082 & 0.0950 & 0.0123 & 0.0130 & 0.0773 \\
\hline & \multicolumn{4}{|c|}{$p_{4}$} & \multicolumn{2}{|l|}{$p_{5}$} & \multicolumn{3}{|c|}{ Employment expectation } \\
\hline & $C_{41}$ & $C_{42}$ & $C_{43}$ & $C_{44}$ & $C_{51}$ & $C_{52}$ & $\begin{array}{l}\text { Higher } \\
\text { school }\end{array}$ & Enterprise & $\begin{array}{c}\text { Civil } \\
\text { servant }\end{array}$ \\
\hline$C_{11}$ & 0.0000 & 0.0000 & 0.0407 & 0.4287 & 0.0000 & 0.0000 & 0.0095 & 0.0297 & 0.0293 \\
\hline$C_{12}$ & 0.0000 & 0.0000 & 0.0219 & 0.0715 & 0.0000 & 0.0000 & 0.0205 & 0.0622 & 0.0516 \\
\hline$C_{21}$ & 0.0000 & 0.0000 & 0.0000 & 0.0000 & 0.0000 & 0.0000 & 0.0261 & 0.0090 & 0.0120 \\
\hline$C_{22}$ & 0.0000 & 0.0000 & 0.0000 & 0.0000 & 0.0000 & 0.0000 & 0.0267 & 0.0045 & 0.0121 \\
\hline$C_{23}$ & 0.0000 & 0.0000 & 0.0000 & 0.0000 & 0.0000 & 0.0000 & 0.0418 & 0.0200 & 0.0265 \\
\hline$C_{24}$ & 0.0000 & 0.0000 & 0.0000 & 0.0000 & 0.0000 & 0.0000 & 0.0446 & 0.0062 & 0.0056 \\
\hline$C_{31}$ & 0.0000 & 0.0000 & 0.0000 & 0.0000 & 0.0000 & 0.0000 & 0.0078 & 0.0417 & 0.0387 \\
\hline$C_{32}$ & 0.1091 & 0.0000 & 0.0000 & 0.0000 & 0.0000 & 0.0000 & 0.0095 & 0.0138 & 0.0110 \\
\hline$C_{41}$ & 0.0000 & 0.3964 & 0.0000 & 0.0000 & 0.0000 & 0.0000 & 0.0428 & 0.0348 & 0.0062 \\
\hline$C_{42}$ & 0.0000 & 0.0000 & 0.0000 & 0.0062 & 0.0000 & 0.0000 & 0.0047 & 0.0092 & 0.0185 \\
\hline$C_{43}$ & 0.0000 & 0.0000 & 0.5444 & 0.0000 & 0.0000 & 0.0000 & 0.0184 & 0.0219 & 0.0413 \\
\hline$C_{44}$ & 0.0000 & 0.0000 & 0.0000 & 0.0000 & 0.0000 & 0.0000 & 0.3773 & 0.3519 & 0.3455 \\
\hline$C_{51}$ & 0.0000 & 0.0000 & 0.0000 & 0.0000 & 0.0000 & 0.0000 & 0.0601 & 0.0697 & 0.0383 \\
\hline$C_{52}$ & 0.0000 & 0.0000 & 0.0000 & 0.0000 & 0.0000 & 0.0000 & 0.0953 & 0.1107 & 0.1485 \\
\hline $\begin{array}{l}\text { Higher } \\
\text { school }\end{array}$ & 0.0640 & 0.1049 & 0.1570 & 0.0482 & 0.0482 & 0.0662 & 0.0000 & 0.0429 & 0.1611 \\
\hline Enterprise & 0.2976 & 0.2907 & 0.2490 & 0.1771 & 0.1771 & 0.1517 & 0.0359 & 0.0000 & 0.0537 \\
\hline Civil servant & 0.1381 & 0.6044 & 0.5940 & 0.0217 & 0.0217 & 0.0289 & 0.1788 & 0.1718 & 0.0000 \\
\hline
\end{tabular}

Through the calculation, three types of employment expectation of relative local priority number are $28.1 \%, 56.6 \%$, and $15.6 \%$. In the process of calculation can be informed, the weight of each factor that impacts on various employment expectations were:

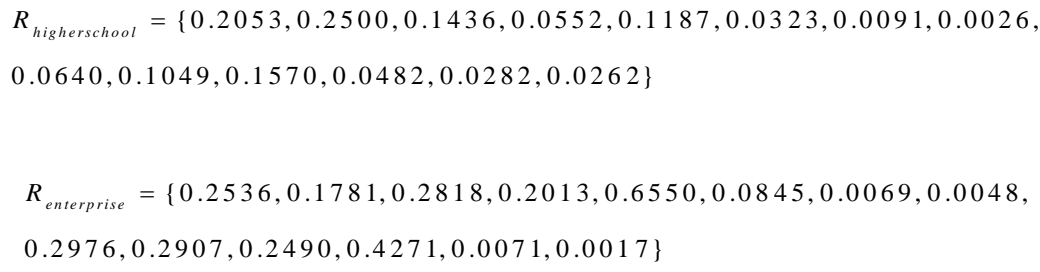




\section{Conclusion}

In this study, three kinds of university graduates employment expectations were predicted, and in the process of calculation, the weight of each factor that impacts on various employment expectations could be informed.

However, this study also has shortcomings: firstly, because the network hierarchy method, there are some subjective results; secondly, in this paper, the investigation is greatly restricted for the number of experts and college graduates; thirdly, the college students' employment expectation classified into three categories has certain limitations. These issues will be solved in the future research.

\section{References}

[1] "MYCOS Research Institute Employment Blue Book 2011 employment report Chinese", [M], Social Science Document Press, vol. 6, (2012).

[2] "MYCOS Research Institute Employment Blue Book 2012 employment report Chinese", [M], Social Science Document Press, vol. 6, (2013).

[3] Roessner and J. David, "Technological Forecasting and Social Change", [J], System Engineering Theory and Practice, vol. 28, no. 3, (1985) Nov, pp. 203-216.

[4] "The Way Forward", [C], 2011 3rd International Congress on Engineering Education: Rethinking Engineering Education, ICEED, (2011), pp. 203-207.

[5] I. Gaballah, "Education pattern reform direction of the European Union", [J], JOM, vol. 54, no. 11, (2002) November, pp. 24-32.

[6] Z. Xiangchang, "Correlation analysis of College Students' employment expectation and the actual employment", [J], Higher education exploration, no. 2, (2007), pp. 110-112.

[7] Z. Xiaomei, L. Xi and D. Tongda, "Structure of employment of college students is expected", [J], Journal of East China Jiaotong University, vol. 29, no. 5, (2012), pp. 100-105.

[8] Z. Xiaomei, "The new generation of College Students' employment expectations influence factor analysis", [J], Journal of East China Jiao tong University, vol. 29, no. 5, (2011), pp. 80-85.

[9] L. Xiaoyu, "Changes of the relationship between gender and work experience and employment", [J], System Engineering Theory and Practice, no. 5, (2008)

[10] C. Hang, "Investigation and Analysis on the employment of graduates majoring in Physical Education", -- Taking Xi'an Physical Education University Department of physical education graduates of 2013 as an example, [J], Science and technology in modern physical education, no. 3, (2013).

[11] C. Peijun, "Analysis and trend of employment ability of medical students of non medical colleges", [J], China folk medicine, no. 5, (2013).

[12] Y. Lin and L. Lin, "Investigation and analysis of students of our school employment trends", [J], Researches in medical education, no. 6, (2007).

[13] C. Bingquan and L. Yunfeng, "Perplexity and Countermeasures of the employment of medical students of non medical colleges", [J], Journal of South China, no. 6, (2009).

[14] X. Hua, "Investigation of College Students' employment expectation, taking tourism management major as an example", [J], Modern Business Trade Industry, no. 11, (2013).

[15] Z. Xiangyu, "What is your salary", [N], Guangzhou daily, no. 7.30, (2012).

[16] L. Yijia, "Significance of Xinjiang medium occupation school graduates employment expectations and the reality of", [J], Innovation Education, no. 6, (2012).

[17] T. Wei, "Graduates most valued "occupation development prospects", [N], Xiaoxiang Morning, no. 7.11, (2012).

[18] L. Na, "The influence of employment expectations and learning motivation of College Students", [J], Journal of Chifeng University (NATURAL SCIENCE EDITION), no. 4, (2013).

[19] R. Caihua, "Analysis of professional full-time graduate employment status and influence factors of physical education and training in HeBei Province", [R], He Bei Normal University, (2008).

[20] Z. Yicai, "Analysis of the factors affecting the employment of female college students", [J], Higher education development and evaluation, no. 5, (2011).

[21] T. L. Saaty, "The Analytic Hierarchy Process", [J], McGraw-Hill, INC, (1980).

[22] T. L. Saaty, "Decision Making With Dependence and Feedback", [J], RWSPublication, Pittsburgh, PA, (1996).

[23] W. Lianfen, "The theory and algorithm of ANP", [J], Systems engineering theory \& Practice, no. 3, (2001). 
[24] C. Jianye, "Application of AHP and ANP in PHRM", [J], Economics and Management School of Tongji University, (2004).

[25] Z. Kun and H. Xiangdong, "ANP network analysis method and its application in portfolio analysis of information system", [J], Journal of Yunnan Institute of Finance and Commerce, no. 4, (2005).

\section{Authors}

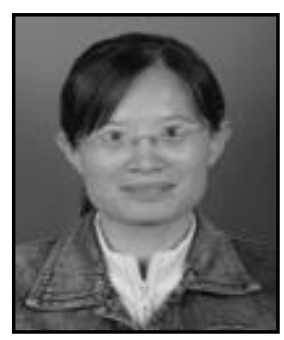

Liying Wang, she received her bachelor's degree of education in Hebei Normal University, Shijiazhuang, Hebei. (2004) and master's degree of science in Tianjin normal university, Tianjin (2008). Now she is a lecturer in Hebei Normal University of Science \& Technology, Qinhuangdao, Hebei. Her current research interests include educational technology, data mining and vocational education.

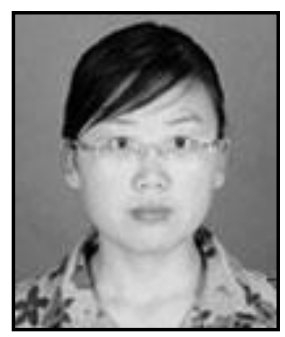

Jianying $\mathbf{L i}$, she received her bachelor's degree of education in Hebei Normal University, Shijiazhuang, Hebei. (2005) and received master's degree of computer technology in Yanshan University, Qinhuangdao, Hebei. (2010). Now she is a lecturer in Hebei Normal University of Science and Technology, Qinhuangdai, Hebei. Her current research interest includes educational technology and vocational education.

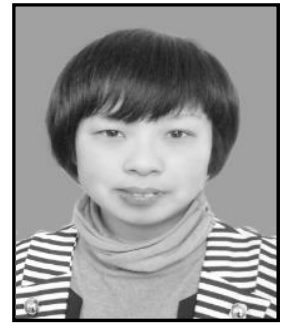

Qiuxiang Shi, she received her bachelor's degree of education in Hebei Normal University, Shijiazhuang, Hebei. (2004) and received her master's degree of computer technology in Yanshan University, Qinhuangdao, Hebei. (2009). Now she is a lecturer in Hebei Normal University of Science \& Technology, Qinhuangdao, Hebei. Her current research interests include educational technology, information technology and vocational education. 